\title{
A Bibliography on Apparel Sizing and Related Issues
}

\section{Y. Tina Lee}

U.S. DEPARTMENT OF COMMERCE

Technology Administration National Institute of Standards and Technology

Manufacturing Engineering Laboratory Factory Automation Systems Division Gaithersburg, MD 20899 



\section{A Bibliography on Apparel Sizing and Related Issues}

\section{Y. Tina Lee}

U.S. DEPARTMENT OF COMMERCE Technology Administration National Institute of Standards and Technology

Manufacturing Engineering Laboratory Factory Automation Systems Division Gaithersburg, MD 20899

February 1994

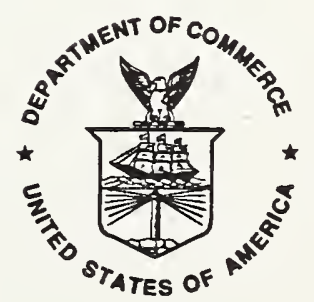

U.S. DEPARTMENT OF COMMERCE Ronald H. Brown, Secretary

TECHNOLOGY ADMINISTRATION Mary L. Good, Under Secretary for Technology

NATIONAL INSTITUTE OF STANDARDS

AND TECHNOLOGY

Arat Prabhakar, Director 



\section{DISCLAIMER}

Certain commercial equipment, instruments, or materials are identified in this paper in order to facilitate understanding. Such identification does not imply recommendation or endorsement by the National Institute of Standards and Technology, nor does it imply that the materials or equipment identified are necessarily the best available for the purpose. 



\title{
A Bibliography on Apparel Sizing and Related Issues
}

\author{
Y. Tina Lee \\ Factory Automation Systems Division \\ Manufacturing Engineering Laboratory \\ National Institute of Standards and Technology \\ Gaithersburg, MD 20899
}

\begin{abstract}
Anthropometric data and sizing systems is an important component of apparel quality. Apparel can not be top quality unless it fits satisfactorily the potential wearers. Much research has been conducted on this topic area. Some of these research results are documented but scattered. The purpose of this report is to collect these documentation/references for the quick use of apparel researchers who are studying sizing and its related issues.

This report presents an annotated bibliography for apparel sizing and related issues. The report lists full bibliographic reference data and a brief abstract or summary for each technical paper or book. The literature collection for the bibliography includes documents from books, journals, reports, and national and international standards.
\end{abstract}

\section{KEY WORDS}

anthropometric; apparel; APDES; body measurements; size designation; sizing

\section{INTRODUCTION}

The apparel industry has used computer systems to great advantage to automate many of its manufacturing processes. However, the manufacturing innovations often stand alone as "islands of automation." Integrating the separate automated processes could greatly improve the effectiveness of the entire enterprise. In recent years, the National Institute of Standards and Technology (NIST), under the sponsorship of the Defense Logistics Agency, has been developing the apparel product data exchange standard (APDES) [1]. The goal of the project is to develop a comprehensive specification for sharing apparel product data among all stages of the product life cycle. We, the APDES project members at NIST, have determined a set of manufacturing data interfaces that could be standardized for the effective integration of the information systems required to operate an apparel manufacturing enterprise [2]. We have also developed an information model for Ready-to-Wear Pattern Making, which is one of the manufacturing data interfaces being identified [3].

Currently, we are working on a Made-to-Measure Pattern Making information model. The first 
task was to conduct a literature survey on Made-to-Measure technology. One of the most critical problems that impact the future development of Made-to-Measure garment is the need for accurate anthropometric data. Hence, we paid great attention to anthropometric data, apparel sizing and related issues when we conducted the survey. The available literature provides a satisfactory amount of information regarding anthropometric measurements, apparel sizing, or fitting, but has little on the current state of Made-to-Measure technology. We believe this is because Made-toMeasure systems are generally developed through industrial efforts and documented only in proprietary manuals.

In conducting the survey, we reached the following conclusion. Many designers, manufacturers, retailers, and customers are concerned that the current apparel sizing systems do not describe the body configurations of today's population. The apparel industry has long awaited reliable and accurate anthropometric data, and the industry needs a consistent and accurate apparel sizing system to increase the quality of ready-to-wear garments.

The purpose of this report is to establish a bibliography on sizing and related issues to support apparel research. The apparel technical papers appear in a wide variety of journals and reports. To begin the technical survey, we consulted several apparel experts and requested papers. We also performed an on-line bibliographic search on the Textile Technology Digest within the Dialog Information Services (DIS) system. We identified eighteen papers related to our topic area from the list generated by the on-line DIS system, using keywords such as measurement, fit, size, anthropometric, etc. After we gathered the first set of technical papers, we then traced the references from those papers. Thus, we built our literature collection. The bibliography in this report is a select list of books, journals, reports and national and international standards from our literature collection.

In the next section, the bibliography section, a total of fifty items are presented. The information presented in each item includes the author(s), title, journal, volume, page(s), publisher, date, and an abstract. If the abstract is directly from the document, it is marked by an asterisk, *. Unmarked abstracts are summaries prepared by the author of this report. 


\section{BIBLIOGRAPHY}

Abend, Jules, “Our Fits Over Fit,” Bobbin, vol.34, \#11, pp. 78-80, July 1993.

This paper presents three apparel designers' debate on some finer points of sizing. These designers include Nicola Tamburrino from Neiman Marcus, George Simonton from For Paris Suits Ltd. and the Fashion Institute Technology, and Linda Ortwein from Kurt Salmon Associates. All agreed that sizing corrections are necessary, but offered different approaches.

Bonney, M. C., K. Case, and J. M. Porter, "User Needs in Computerised Man Models," NATO Symposium on Anthropometry and Biomechanics Theory and Application, 1982.

Models have long been used as part of the design process and they have advantages of cost and speed over other methods both for strategic and operational decision making. Greater computer availability and lower cost means that computer modeling has increasingly been used by designers. Every model is an abstraction and the key to successful modeling appears to be to include in the model only those factors which are relevant to the decision to be made. On the other hand, commonality of needs between problems means that some model attributes are useful for the solution of a range of problems. This paper identifies a set of ground rules for producing a satisfactory man model which integrates the needs of computer aided designers and ergonomists. The paper also proposes a strategy to collect anthropometric data.

Churchill, Edmund, Thomas Churchill, John T. McConville, and Robert M. White, "Anthropometry of Women of the U.S. Army - 1977 Report No. 2 - The Basic Univariate Statistics," U.S. Army Natick Technical Report (Natick/TR-77/024), U.S. Army Natick Research and Development Command, June 1977.

This report, the second in a series, summarizes the univariate statistics obtained in an anthropometric survey of women in the U.S. Army. The survey was conducted at Fort Sam Houston, Texas; Fort McClellan, Alabama; Walter Reed Medical Center, the District of Columbia; and Fort Jackson, South Carolina, during the winter of 1976-1977. Data for 69 body measurements were obtained on a sample of 1,331 women who covered wide ranges of age, rank, and military assignment. Additional data were obtained on between 200 and 300 of the women for: a) other standard body size measurements, b) workspace measurements, c) head and face measurements, and d) static strength measurements. Summary statistics and frequency distributions are given here for all these measurements, plus age. Full descriptions of the measurement techniques and the design and the conducting of the survey appeared in the first of this series of reports. Brief definitions, illustrations of measurements, and outlines of the computational and statistical procedures used in preparing the report are included. 
Clauser, Charles E., Pearl E. Tucker, John T. McConville, E. Churchill, Lloyd L. Laubach, and Joan A. Reardon, “Anthropometry of Air Force Women," Aerospace Medical Research Laboratory Technical Report (AMRL-TR-70-5), Wright-Patterson Air Force Base, April 1972.

This report describes and presents the statistics results of an anthropometric survey of United States Air Force women carried out during 1968. Included in the report are a description of the methods and techniques used in the survey, descriptions of the measuring techniques used, and both uniand bi-variate statistical summaries. A total of 1,905 women was included in this survey sample. The sample was selected from the specific duty stations which offered the highest probability of obtaining a representative cross-section sample of U.S. Air Force women. A total of 137 anthropometric dimensions was measured. This anthropometry included 5 measures of weight and body composition, 30 measures of body height and length, 26 measures of body girth, 15 measures of body breadth and depth, 12 measures of body surface distance, 30 measures of the head and face, 3 measures of the hand, 2 measures of the feet, 1 measure of grip strength, and 13 measures of the subject while she was wearing a foundation garment.

DeLong, Marilyn, Susan Ashdown, Leslie Butterfield, and Karin Frost Turnbladh, "Data Specification Needed for Apparel Production Using Computers," Clothing and Textiles Research Journal, vol. 11, \#3, pp. 1-7, Spring 1993.

*New developments using artificial intelligence and the computer can effect changes in the production of apparel and ultimate consumer satisfaction with apparel products. Much data specification is needed before apparel can be manufactured that quickly and efficiently takes into account the individual body of the customer. Trial and error fitting methods will no longer be economically feasible with such customized production. Garment fit and ease preferences are explored in this research to determine feasibility of an individually fitted, computer generated pant. A customized pair of pants was made for each of 38 female subjects using a computer-aided-design program that took into account the following factors: body size, configuration, alignment, proportions, and preferred ease amounts of the wearer. A level of prediction for ease was achieved with these pants and 27 of 28 of the final subjects rated their pant as satisfactory or very satisfactory following a seven hour wear test.

Dempster, Wilfrid Taylor, Lawrence A. Sherr, and Judith G. Priest, "Conversion Scales for Estimating Humeral and Femoral Lengths and the Lengths of Functional Segments in the Limbs of American Caucasoid Males," Human Biology, vol. 36, pp. 246-262, 1964.

*The study presents a method for finding the lengths of the bones of the arm and thigh in selected living subjects; and it seeks a new group of functionally significant measurements concerning the arm, forearm, thigh, and leg. Individuals vary considerably in the size and relative proportions of such lengths as those which characterize the arm, forearm, thigh, leg, and head and trunk. These dimensions vary also in relation to total stature. Since there is a continuity between adjacent body 
segments, one must decide how to define the end-points for measuring segments. Only bones, since they are discontinuous rigid members, may be regarded as individual units; but in the intact body these are not directly available for observation and measurement. Two factors complicate measurements made on living subjects. First, both circumferential and caliper measurements invariably enclose or span a variety of tissues, hence, they cannot be regarded in a strict sense as fundamental measurements. Second, where postural and functional movements at joints are possible between the end points of a caliper or tape measure, dimensional inconsistencies may be expected and the most rigorously stereotyped measurement techniques are necessary for repeatable measurements.

\section{Dreyfuss, Henry, "The Measure of Man, Human Factors in Design," Whitney Library of Design, 1960.}

Sixteen diagrams based on human dimensions are presented in the report. These diagrams were developed in the course of designing the interiors of airplanes and liners, plumbing fixtures, machine tols, farm and industrial equipment, telephones, and the interiors of combat vehicles and vessels. The categories for these diagrams are: (1) anthropometric data- standing adult male,

(2) anthropometric data- standing adult female, (3) anthropometric data- male and female children,

(4) basic visual data, (5) hand measurements of men, women, and children, (6) foot measurements and basic foot controls, (7) anthropometric data- adult male standing at control board, (8) anthropometric data- adult female standing at control board, (9) anthropometric data- adult male seated at console, (10) anthropometric data- adult female seated at console, (11) anthropometric data- adult male seated in vehicle, (12) human strength, body clearances, climbing data, and ingress and egress, (13) basic display data, and (14) basic control data.

\section{French, G. W., "International Sizing," Clothing Institute Journal, vol. XXIII, pp. 155-162, April 1975.}

This paper can be considered as a status report of the development of ISO standards for garment sizing systems. The author, with the Clothing Manufacturers' Federation of the United Kingdom, presents not only the progress of developing the international sizing standards but also his viewpoints. The standard effort was started in 1970. The effort begun with the developing of standard methods of designating the size of garment. Three working groups were formed. They are men's and boys' wear group, women's and girls' wear group, and infants' wear group. The paper lists control dimensions that are used to designate the size of garments. Proposed methods of indicating sizes using pictograms are also described in the paper. 
Green, Mary E., "An Application of U.S. Army Women's Anthropometric Data to the Derivation of Hypothetical Sizing/Tariffing Systems," Clothing Research Journal, vol. 9, pp. 16-32, 1981.

*Factor analysis of selected sets of body measurements from a reduced battery of 47 variables generated in the U.S. Army women's 1977 anthropometric survey yielded interpretable factors for upper torso, lower torso, and whole torso segments. Applied in a six-step process for deriving hypothetical sizing/tariffing systems, the factors identify the likely key dimensions (step 2) of: upper torso-front waist length and shoulder breadth; lower torso-crotch height and hip circumference; whole torso-bust circumference and crotch height. On-going work on further applications of the process are described briefly.

Grosso, Marc R., Richard D. Quach, Ernest Otani, Jianmin Zhoa, Susanna Wei, Pei-Hwa Ho, Jiahe Lu, and Norman I. Badler, "Anthropometry for Computer Graphics Human Figures," University of Pennsylvania Technical Report (MS-CIS-89-71), October 1989.

*Anthropometry as it applies to Computer Graphics is examined in this report which documents the Anthropometry work done in the Computer Graphics Research Laboratory at the University of Pennsylvania from 1986 to 1988. A detailed description of the basis for this work is given along with examples of the variability of computer graphics human figures resulting from this work. Also discussed is the unique and versatile user interface developed to allow easy manipulation of the data used to describe the anthropometric parameters required to define human figure model. The many appendices contain the specifics of models as well as much of the data used to define the models.

Grosso, Marc R., Richard D. Quach, and Norman I. Badler, "Anthropometry for Computer Animated Human Figures," Proceedings of Computer Animation '89: State-of-the-art in Computer Animation, pp. 83-96, 1989.

*Anthropometry as it applies to the creation and articulation of computer graphics human figures is examined. Necessary concepts for computer models of animated people suitable for engineering animation environments are discussed, including joints, joint limits, mass, moment of inertia, and volume. A versatile spreadsheet-like user interface is described that permits the simple manipulation of the data used to specify anthropometric parameters. Different populations are easily utilized. Examples of various percentile male and female figures sized from a particular database illustrate the system's capability. 
Jay, Aubrey, "The Reasons for Variations in Fit of Garments and Their Relations to Quality Control," Textile Quality Control, vol. 16, pp. 16-22, 1969.

Two distinct methods of obtaining garment size are introduced. (1) Garment Size is defined as USDCBS + $(\mathrm{O} / \mathrm{S})+(\mathrm{F}+\mathrm{S}) ; \quad(2)$ Garment Size is defined as IBF $+(\mathrm{O} / \mathrm{S})+(\mathrm{F}+\mathrm{S})$; where USDCBS stands for Body Standards of U.S. Department of Commerce, O/S stands for Oversize, F stands for Fit, S stands for Style and IBF stands for Industry Body Forms. While the body forms are based on the government body standards, they are an interpretation of these dimensions and vary by manufacturer. The first method is used in the Men's and boys' apparel industry; while the second method is used in the women's and girls' industry. $\mathrm{O} / \mathrm{S}$ is the additional fabric required to go around the body. F+S, fit and style, is the additional dimension to achieve comfort and the styling effect to make saleable garments. Other factors which are dependent on the experience of the master pattern makers, for example, fabric type, and end use of garment, will then be added to each method.

Korna, M., P. Krauskopf, D. Haddox, S. Hardyal, M. Jones, J. Polzinetti, and J. W. McDaniel, "User's Guide For Crew Chief: A Computer Graphics Simulation of an Aircraft Maintenance Technician (Version 1 - CD 20)," Armstrong Aerospace Medical Research Laboratory Technical Report (AAMRL-TR-88-034), Armstrong Aerospace Medical Research Laboratory, Wright-Patterson Air Force Base, May 1988.

This User's Guide describes the procedures to operate the Harry G. Armstrong Aerospace Medical Research Laboratory's and Air Force Human Resources Laboratory's CREW CHIEF system of programs. The CREW CHIEF system of programs is a computer graphics simulation of the physical characteristics and capabilities of Air Force maintenance technicians. It provides for designers a tool for early identification of design-related maintainability problems. The system of programs is interactive with the Computer-Graphics Aided Design and Manufacturing (CADAM) software package. The user should be knowledgeable in CADAM operations, as CADAM interactions are not included in this document. The User's Guide includes an introduction to the technician model (man-model) and the conventions used to develop and analyze the interactions of the man-model's physical characteristics and capabilities with the elements of the work station.

Kuhlmann, Peter, "Non-Contact Body Measurement - An Essential Tool to Quick Response," Proceedings of the 15th International Apparel Research Conference - Advanced Apparel Technologies: Blueprint for the Future, American Apparel Manufacturers Association, October 1988.

This paper describes the Technotailors' non-contact measuring system. The system is based on techniques adapted from classical and moire interferometry. The approach of the techniques is known as Phase Measuring Profilometry (PMP). A PMP based system can optically scan a standing human being in one half second and produce a high resolution 360 degree output in under one minute. Specific dimensions, shape, slope, sections, etc. can be obtained real-time through an 
interactive mouse operated system. Certain dimensional parameters can be extracted automatically. The information is digital; it can be transmitted by modem to remote locations.

\section{LaBat, Karen L., "Improving Garment Fit - A Challenge for Industry," ASQC Quality Congress Transactions, American Society For Quality Control, pp. 377-382, May 1989.}

A questionnaire was developed and administered to 107 female subjects to study consumer satisfaction/dissatisfaction with the fit of ready-to-wear clothing. The ages of the sample ranged from 18 to 40 years. The sample represents a segment of society that shows high interest in fashion and apparel, and spends disposable income on clothing. Most subjects wore clothing in the size ranges Misses 8-10 and Junior 9-11. Results indicated that this sample was not very satisfied with the fit of ready-to-wear. Subjects were frustrated with the shopping process to find clothing that fits their individual bodies. These subjects were least satisfied with lower body fit. Subjects voiced two concerns through open-ended response questions: 1 ) that current sizing system do not reflect real female proportions, and 2) that the size of a garment is not clearly communicated through labeling. Continuing improvement in quality apparel requires that manufacturers seriously consider improving fit of garments. Methods for improving sizing systems include careful definition of the target market, including physical dimensions and using up-to-date information on body dimensions and fit.

\section{Lane, Marianne, "Preliminary Findings of Study Explain Why Clothes Don't Fit Some Women 55 and Older," ASTM Standardization News, p. 19, November 1992.}

This report briefs the ASTM project: Development of Body Measurement Tables for Women 55 Years and Older. The objective of the project was to determine if differences exist in current body measurements of women aged 55 and older compared to those listed in the Voluntary Product Standard PS 42-70 "Body Measurements for the Sizing of Women's Patterns and Apparel." Another objective was to determine which body dimensions of women aged 55 and over are related to garment fitting problems. Through measurement of 7,000 women volunteers, early findings show that shoulder ball joints roll forward, the abdomen tends to rise and protrude, the waistline thickens and rises, and the derriere flattens.

Lee, Philip, Susanna Wei, Jianmin Zhao, and Norman I. Badler, "Strength Guided Motion," University of Pennsylvania Technical Report (MS-CIS-90-04), University of Pennsylvania, 1990.

*A methodology and algorithm is presented that generates motions imitating the way humans complete a lifting task under various loading conditions. The path taken depends on natural parameters: the figure geometry, the given load, the final destination, and especially, the strength model of the agent. Additional user controllable parameters of the motion are the comfort of the 
action and the perceived exertion of the agent. The algorithm uses this information to incrementally compute a motion path of the end effector moving the load. It is therefore instantaneously adaptable to changing force, loading, and strength conditions. Various strategies are used to model human behavior that compute the driving torques as the situation changes. The strength model dictates acceptable kinematic postures. The resulting algorithm offers torque control without the tedious user expression of driving forces under a dynamics model. The algorithm runs in near real-time and offers an agent-dependent toolkit for fast path prediction. Examples are presented for various lifting tasks, including one- and two-handed lifts, and raising the body from a seated posture.

McConville, John T., "Chapter 8, Anthropometry in Sizing and Design, from Anthropometric Source Book Volume I: Anthropometry for Designers," NASA Reference Publication 1024, pp. VIII 1-23, National Aeronautics and Space Administration, Scientific and Technical Information Office, 1978.

The Anthropometric Source Book, a three-volume book, is designed to provide the aerospace industry, government agencies and a wide variety of industrial users with a comprehensive tabulation of anthropometric data. It is tailored to meet the needs of engineers engaged in the design of equipment, habitability areas, workspace layouts, life-support hardware, and clothing for the NASA Space Shuttle/Spacelab program. The intent is to provide the designer not only with dimensional data but with underlying anthropometric concepts and their application to design. All available anthropometric data collected in the weightless environment are documented in this book, which also includes an extensive tabulation of anthropometric data defining the physical size, mass distribution properties, and dynamic capabilities of U.S. and selected foreign populations. Volume I is a nine-chapter treatment covering all basic areas of anthropometry and its applications to the design of clothing, equipment, and workspace. One chapter is devoted to discuss the application of human body-size diversity and qualification to engineering design. Procedures are outlined for using anthropometric data in the development of effective sizing programs.

\section{Palaganas, Dee, “Uni-Sizing Europe,” Apparel Industry Magazine, pp. 82-88, September 1991.}

In preparation for the opening of the European market in 1992, the European garment industry is proposing standard sizes for clothing. These sizes will eliminate the confusion that currently exists among countries and individual apparel designers. The Swissfashion, the central association of the Swiss clothing industry, directed a study that recommends European sizing standards tailored to the needs of consumers, retailers and manufacturers. Four guidelines were developed as the basis for the new European sizing standards. These guidelines are the use of body sizes as anthropometric characteristics, the use of the metric system, the application of key body-related control dimensions, and the use of pictograms to overcome language barriers. Several fixed body control dimensions were developed in accordance with similar ISO control dimensions as a basis 
for sizing tables. A shortened size designation was also introduced by the association. The new standards only specify body measurements, not clothing sizes. U.S. manufacturers may need to incorporate onto the label the body control dimensions, in the metric system, for which the garment is designed.

Paquette, Steven P., "Human Analogue Models for Computer-Aided Design and Engineering Applications," Army Natick Technical Report (NATICK/TR-90/054), United States Army Natick, November 1990.

*A review of six computerized human analogue models (SAMMIE, COMBIMAN, CREW CHIEF, CAR, JACK, and SAFEWORK) was conducted to identify the state-of-the-art in ergonomic modeling software. All of the models included here demonstrate some utility as ergonomic design tools and were developed so that material designers and engineers can conduct preliminary human factors analysis prior to prototype construction. These human figure models vary widely with respect to primary function and analytical capabilities. However, they essentially fall within one or more of the following categories: anthropometric accommodation analysis, biomechanical/strength modeling, or human-machine interface analysis. This report includes the developmental background of each model, the hardware requirements, and the major functions provided by each system, e.g., reach/clearance analysis, vision analysis, strength modeling, and computer simulation. The underlying anthropometric databases that support model generation are also reviewed. In addition, the techniques used to construct the human figures in terms of skeletal link structure and geometric representation of body segment shape and volume are discussed. Finally, some challenges are presented that confront future refinement of human figure models.

Patterson, Carol A. and Jessie Warden, "Selected Body Measurements of Women Aged Sixty-Five and Older," Clothing and Textiles Research Journal, vol. 2, pp. 23-31, 1983-1984.

The purpose of this study was to determine if the body measurements of a sample of women aged 65 and over are adequately presented in the garment-sizing system. The survey sample included 205 women volunteers aged 65 to 96 , with a mean of 73.9. Thirty-three selected body measurements were taken on each woman and the results were analyzed and compared with the O'Brien and Shelton's 1941 study on which the Voluntary Product Standard PS 42-70 "Body Measurements for the Sizing of Women's Patterns and Apparel" was based. Of the 33 measurements, 25 were significantly different from body measurements in the old study. Among those found to be dissimilar were bust, waist, abdominal extension, and hip girth measurements. Statistical analysis yielded body measurements that could be used as key indices for reliably predicting other body measurements. From these indices, five alternative sizing systems were developed: height/weight, height/bust, weight/waist height, bust/waist height, and abdominal extension/waist height. One horizontal and one vertical measurement were selected for each sizing system. 
Pfister, Henry L. and Henry D. Pfister, "Noncontact Body Measurement for Automated Apparel Manufacturing," Proceedings of Factory Automation and Information Management Conference, Ireland, March 1991.

*A noncontact body measurement system has been designed and demonstrated for the apparel industry as part of an automated apparel manufacturing program. The measurement system uses digitized video images and multiple body views with a desktop computer to create standard tailor measurements. Digital image processing is used to detect body features, register the multiple images, and compute the tailor measurements. The measurement data is used by automated apparel manufacturing to produce a made to measure product with the cost advantages of just in time manufacturing.

Phillips, Cary B. and Norman I. Badler, "Jack: A Toolkit for Manipulating Articulated Figures," Proceedings of the ACM SIGGRAPH Symposium on User Interface Software, pp. 221-229, ACM Press, October 1988.

*The problem of positioning and manipulating three dimensional articulated figures is often handled by ad hoc techniques which are cumbersome to use. This paper describes a system which provides a consistent and flexible user interface to a complex representation for articulated figures in a $3 \mathrm{D}$ environment. Jack is a toolkit of routines for displaying and manipulating complex geometric figures, and it provides a method of interactively manipulating arbitrary homogeneous transformations with a mouse. These transformations may specify the position and orientation of figures within a scene or the joint transformations within the figures themselves. Jack combines this method of 3D input with a flexible and informative screen management facility to provide a user-friendly interface for manipulating three dimensional objects.

Rains, Ron, Brenda Girton, Brad Kimble, Peter Chen, and Liisa Kirjavainen, "Measurement Specification Document - Womens' Edition," Microdynamics PAS Committee, August 1992.

This document defines circumference locations, measurement points, and measurement distances of the human body which are necessary in the manufacturing and fitting of women's apparel. A circumference is a circular measurement around a certain part of the body. The starting point of the circumference measurement is the same as its ending point. A measurement point is a location point on the human body. The point has 3 properties: height, width, and depth. A measurement distance measures the distance along the body between two measurement points. The measurements are defined in terms of two different types of applications: human application (for the human user, someone who will take body measurements required to customize garment sizes for an individual) and computer application (for the computer, which will process these measurements in order to produce a piece of apparel specifically for the individual). 
Rains, Ron, Brenda Girton, Brad Kimble, Peter Chen, and Liisa Kirjavainen, "Measurement Specification Document - Mens' Edition," Microdynamics PAS Committee, August 1992.

This document defines circumference locations, measurement points, and measurement distances of the human body which are necessary in the manufacturing and fitting of men's apparel. A circumference is a circular measurement around a certain part of the body. The starting point of the circumference measurement is the same as its ending point. A measurement point is a location point on the human body. The point has three properties: height, width, and depth. A measurement distance measures the distance along the body between two measurement points. The measurements are defined in terms of two different types of applications: human application (for the human user, someone who will take body measurements required to customize garment sizes for an individual) and computer application (for the computer, which will process these measurements in order to produce a piece of apparel specifically for the individual).

\section{Rodwell, Wilfred, "Metrication as It Will Affect the Clothing Industry," Clothing Institute Journal, vol. XVIII, pp. 131-143, February 1970.}

This paper discusses those aspects of metrication that will affect both the sizes and nomenclature of clothing. The effect of metrication will be on the manufacturers, the retailers, and most importantly the general public. For the manufacturer, the major effect of going metric will be felt in the design and pattern departments. However, quality control could greatly benefit from these changes; metrication could provide the stimulus to rationalize the quality control department. The paper discusses different issues of the metrication for different branches, that include children's wear, women's wear, and men's wear.

\section{Roozbazar, Aziz, "Biomechanical Modeling of the Human Body," Proceedings of the Seventeenth Annual Meeting of the Human Factors Society, pp. 181-191, 1973.}

The purpose of this paper is to review different approaches to the biomechanical modeling of the human body. In this paper, the models have been divided into biodynamic, mathematical, kinematic/kinetic, and computer models. These four classifications are for descriptive purposes only because in reality these models overlap, or encompass each other. The emphasis is with the modeling of the whole body rather than components of it, and therefore models concerned with specific components of the body such as bones, spine, skull, or muscles are not covered.

Rothwell, Patricia L. and Dianne T. Hickey, "Three-Dimensional Computer Models of Man," Proceedings of the Human Factors Society - 30th Annual Meeting, pp. 216-220, 1986.

This paper addresses two issues. First, it outlines several problems associated with obtaining information regarding the availability and content, the classification, nomenclature, and currency 
of computer man-modeling programs. Second, it provides evidence as to why the computer manmodeling technology is advantageous to traditional workspace design methods in representing the user population and responding to design developments in a timely and interactive fashion.

Salusso-Deonier, Carol J., “Gaining a Competitive Edge with Top Quality Sizing,” ASQC
Quality Congress Transactions, American Society for Quality Control, pp. 371-378, 1989.

For over 50 years, apparel sizing has been both inconsistent and inaccurate. Current sizing standards rely on obsolete body measurement databases. Body forms used to translate sizing into garment styles do not represent potential consumers' body dimensions, contours or posture. Top quality apparel sizing cannot occur until sizing is both reliable and accurate. Potential sclutions to the accuracy dilemma are explored in this report. To be successful, industry needs a solution which virtually duplicates common variations in the human form. A national body measurement data bank would be invaluable in the design of all types of consumer products. Besides, dress forms need to be revised to reflect body type differences in posture and contour.

Salusso-Deonier, Carol J., Marilyn R. DeLong, Frank B. Martin, and Karl R. Krohn, "A Multivariate Method of Classifying Body Form Variation for Sizing Women's Apparel," Clothing and Textiles Research Journal, vol. 4, \#1, pp. 38-45, 1985-1986.

*The purpose of this study was to develop a multivariate method for structuring a sizing system for women's apparel. The 1977 survey of U.S. Army women was the database. The sample was limited to 1217 subjects who were White or Black and 17-35 years old. The methodology underlying PS 42-70, the current U.S. sizing standard, was studied relative to recent changes in body form classification, apparel production, and merchandising which support development of multivariate methodology. Examination of PS $42-70$ as a classification system for the sample showed inadequate proportioning of overall body dimensions, particularly shoulder breadth and body segment lengths. The experimental method used components 1 and 2 to summarize body form variation as the relationship between body thickness and length. A Principal Component Sizing System (PCSS) was constructed by partitioning the distribution of principal components 1 by 2 into 26 sizes. A per subject comparison of "goodness of fit" of PS 42-72 and PCSS showed PCSS consistently closer to subjects' overall body proportions than PS 42-70. The multivariate relationship between body thickness and length is fundamental to body form and size variation. The results indicate that PCSS better represents that relationship for the sample studied.

Salusso-Deonier, Carol J., Nancy L. Markee, and Elaine L. Pedersen, "Developing Realistic Stimuli for Assessing Observers' Perceptions of Male and Female Body Types," Perceptual and Motor Skills, vol. 72, pp. 603-610, 1991.

*The goal of this research was to create more realistic stimuli for research in assessing observers' 
perceptions of male and female body types. Stimuli were developed by classifying large samples of photographs and using representative photographs to illustrate body types. Resultant stimuli go beyond current stereotypic stimuli to provide realistic representations of commonly occurring body types among men and women ages 18 to 40 years. Realistic stimuli can be used in a wide range of research both to understand observer perceptions and to teach the reality of human variation.

Shannon, Elizabeth and Naomi Reich, "European Study Tour Review of Clothing \& Textile Comfort Research," Association of College Professors of Textiles and Clothing Proceedings, pp. 197-204, October 1985.

A study tour was conducted to review the area of comfort in relation to clothing and textiles. Four European institutions were visited. These institutions carry out a combination of activities which include developing testing standards and performing pure and applied research. Research topics include sizing systems and comfort of textiles and clothing. This paper addresses these research topics involved at each institute. The European trend towards expanding sizing systems to include other figure types and conditions, such as the elderly and handicapped people. This is of special concern for institutions actively involved in research activities. The current research endeavors towards a clearer understanding of the complex nature of clothing comfort will contribute valuable information for both textile production and clothing design. The development of testing procedures for evaluating comfort factors in clothing assemblies will provide important data for designers, manufacturers and researchers.

Shen, Lewen and Janice Huck, "Bodice Pattern Development Using Somatographic and Physical Data," International Journal of Clothing Science and Technology, vol. 5, \#1, pp. 616, 1993.

This paper describes a research work performed at the Kansas State University. The study attempted to use a theoretical basis of dart theory, in combination with photograhpic data and limited body measurements, to develop a bodice front and back pattern for the female upper torso. Somatometry is a method to describe graphically the human body shape and it has been used in the development of two-dimensional patterns. Somatographs have been used to determine body angles and curves. The methodology offers the potential of providing more accurate measurements than traditional methods of body measurements.

Staples, Nancy J., J. Stephen Davis, and Roy P. Pargas, "Automated Size Prediction for Try on of U.S. Army Men's Initial Dress Uniform," Proceedings of the Fourth Annual Academic Apparel Research Conference, February 1993.

This report presents an on-going study at Clemson University to automate the prediction of U.S. Army male dress uniform initial issue try-on size. The research plan is to develop and calibrate 
expert system software which uses body dimensions as input and predicts the appropriate garment size for try on. The system will be tested using body measurements taken by fitters at Fort Jackson CIIP. When the system is running smoothly, incorporation of a 3-dimensional, non-contact body scanning device being developed and provided by the Dimensional Measurement System Inc. will further improve the fitting process by replacing the manual measurement taking. The measurements will be fed to the expert system and the size predictions will be printed out for each soldier. A part of the project objective is to develop a software library of display and measurement tools to make useful the output of a 3D body scan. These tools should allow the user to view the body image from an arbitrary angle and to take a variety of measurements.

Tamburrino, Nicola, “Apparel Sizing Issues,” Bobbin, vol. 33, \#8, April - June 1992.

This article presents a history of sizing and proposes an approach that could result in less confusion for the consumer and retailers and other distributors of apparel goods. Proposed solutions for apparel sizing system include: 1) establish standard labeling information which allows the consumer to verify the dimensions of the garment, 2) allow manufacturers the freedom to use any dimensions, provided they comply with the preceding proposed labeling standard, and 3) encourage the establishment of industry funding for the continuous survey of regional anthropometric data.

Woodson, Eleanor M. and Patricia E. Horridge, "Apparel Sizing As It Relates to Women Age Sixty-five Plus," Clothing and Textiles Research Journal, vol. 8, \#4, pp. 7-13, Summer 1990.

*The purposes of this study were (a) to compare body measurements of women 65 years of age or older to body measurements listed for commercial basic patterns and Voluntary Product Standard PS 42-70, and (b) to produce computerized basic patterns from these 65-plus miilsurements and to compare them with commercial basic patterns. Participants were 104 volunteer, ambulatory women, age 65 years or older, residing in residential housing or life-care communities in Texas. Vertical and horizontal body measurements were taken from a computerized Body Graph Measuring Device placed on the participant. Sample computerized patterns were drafted for sizes in which five or more participants were included. Findings showed differences between the measurements of the sample and the measurements of PS 42-70 and commercial basic apparel patterns. Due to the variation of the body measurements and diversity of posture of the 65-plus woman, needed adjustments were not confined to vertical and horizontal measurements but included adjustments of additional curvatures of the body. 
Workman, Jane E., "Body Measurement Specifications for Fit Models as a Factor in Clothing Size Variation," Clothing and Textiles Research Journal, vol. 10, \#1, pp. 31-36, Fall 1991.

The purpose of this research was to investigate one factor which contribute sizing variation, body measurement specification for fit models. The focus was to determine current standards for size 8 and 10 fit models; to compare body measurement specifications for size 8 fit model with size 10 fit model; and to compare body measurement specifications for size 8 and 10 fit models for a 10year span - 1976 to 1986. Data for the study were collected from trade journal advertisements for size 8 and 10 fit models. Results of this study reveal a lack of standardization with regard to body measurement specifications for fit models within the apparel industry. A 1986 size 10 had significantly larger hip measurement specifications than a 1986 size 8 . A comparison of 1986 and 1976 specifications revealed only one difference - hip measurement specifications for the 1986 size 10 were significantly larger than for the 1976 size 10. A comparison of the range of measurement specifications between 1976 and 1986 revealed that a wider range existed in 1986 for both sizes 8 and 10 than existed in 1976.

\section{"Standard Tables of Body Measurements for Infants, Ages 0 to 18 Months," ASTM Designation: D 4910-89, American Society of Testing and Materials, 1989.}

This standard lists body measurements of infants from birth to 18 months. Although the measurements are body measurements, they can be used in designing apparel for infants in this age range when taking into account such factors as fabric type, desired ease of body movement, styling, and fit. The standard was developed from data published by the U.S. Department of Commerce. These data were based on original research conducted by the U.S. Department of Agriculture in the 1930 's. This standard takes into consideration children's growth pattern reflected in the 1980 charts for the National Center for Health Statistics and the 1977 Anthropometric Study of U.S. Infants and Children conducted by the University of Michigan. All sudden shifts of proportion have been eliminated so as to reflect the gradual growth and development of the child from birth to adolescence. Two tables, one with metric units and another with inch-pound units, are presented in this standard. The values stated in either acceptable metric units or in other units shall be regarded separately as standard. The values stated in each system may not be exact equivalents; therefore, each system must be used independently of the other, without combining values in any way.

"Ergonomic Models of Anthropometry, Human Biomechanics, and Operator-Equipment Interfaces," Proceedings of the Workshop on Integrated Ergonomic Modeling, National Academy Press, 1988.

The Committee on Human Factors convened a two-day workshop on June 17 and 18, 1985, in Washington D. C., to assess the feasibility of developing an integrated ergonomic model. Fifteen experts in anthropometry, biomechanics, bioengineering, work physiology, human factors 
engineering, psychomotor performance, computer modeling, and system design and operation participated in the workshop. Background papers were provided in advance for each of the three modeling domains: anthropometric, biomechanical, and interface. In addition, the participants prepared brief position papers for distribution prior to the workshop. These background and position papers, workshop deliberations, and follow-up materials constitute the basic elements of this project report. The report describes the current status of development of anthropometric, biomechanical, and interface models, giving limitations and listing research needs specific to each. Approaches to the development of integrated ergonomic models and research recommendations for further development of lower-level models are discussed in the report.

"Size Designation of Clothes - Men's and Boys' Outerwear Garments," ISO 3636, ISO, TC 133, 1977.

*This International Standard establishes a system of designating the sizes of men's and boys' outerwear garments (including knitwear and swimwear) that are classified as (a) covering the upper or the whole body, or (b) covering the lower body only, and applies to civilian and uniform garments. Both the control dimensions on which the size designation system is based and the method of indicating the size designation on a garment label are laid down.

\section{"Size Designation of Clothes - Women's and Girls' Outerwear Garments," ISO 3637, ISO, TC 133, 1977.}

*This International Standard establishes a system of designating the sizes of women's and girls' outwear garments (including knitwear and swimwear) that are classified as (a) covering the upper or the whole body, or (b) covering the lower body only, and applies to civilian and uniform garments. Both the control dimensions on which the size designation system is based and the method of indicating the size design nation on a garment label are laid down.

\section{“Size Designation of Clothes - Infants' Garments,” ISO 3638, ISO, TC 133, 1977.}

*This International Standard establishes a system of designating the sizes of infants' garments. Both the control dimension on which the size designation system is based, and the method of indicating the size designation on a garment label, are laid down.

\section{"Garment Construction and Anthropometric Surveys - Body Dimensions," ISO 8559, ISO, TC 133, 1989.}

*This international standard defines the location of body dimensions taken on anthropometric 
surveys and for the preparation of garment patterns and garment stands, and specifies a standard procedure for measuring the body. The location and taking of body dimensions appropriate to all items of clothing and accessories for all population groups are covered in this International Standard. The use of calipers and horizontally oriented anthropometers to determine width dimensions is excluded. Not all the body dimensions defined in this International Standard are always necessary during anthropometric surveys or in the manufacture of clothes.

\section{“Standard Sizing Systems for Clothes," ISO/TR 10652, ISO, TC 133,1991.}

*This technical report establishes a body sizing system to be used for compiling standard garment sizes for infants, men and boys, women and girls. Garment dimensions are not contained in this report.

"Body Measurements for the Sizing of Apparel for Infants, Babies, Toddlers and Children (For the Knit Underwear Industry)," Commercial Standard (CS151-50), National Bureau of Standards, June 1953.

This Commercial Standard establishes a system of designating the sizes of infants', babies', toddlers' and children's apparel for the guidance of those engaged in producing or preparing specifications for ready-to-wear garments and patterns. The standard includes classification, size designations and body measurements. This standard also covers definitions of the important landmarks, methods of measure and recommended methods of determining lengths of dresses, coats, skirts and slacks (outseams) from appropriate body measurements.

\section{"Body Measurements for the Sizing of Boy's Apparel," NBS Voluntary Product Standard (PS 36-70), National Bureau of Standards, December 1971.}

*This Voluntary Product Standard covers standard size designations, size classifications, and body measurements for the sizing of boys' apparel. The standard includes sections on applications of the system, recommended methods of identification, methods of measuring, and clothing allowances. The measurements given in this standard are body, not garment, measurements.

\section{"Body Measurements for the Sizing of Women's Patterns and Apparel," NBS Voluntary Product Standard (PS 42-70), National Bureau of Standards, September 1971.}

*This Voluntary Product Standard covers standard size classifications, size designations, and body measurements to aid in the consistency of sizing of women's apparel and, by doing so, provides a means for the consumer to identify her body type and size for proper fit. This standard also covers 
applications of the system, definitions, methods of measurement, adjustments to compensate for the effect of foundation garments, spanning charts, and a recommended method of identification. The measurements given in this standard are body, not garment, measurements.

"Body Measurements for the Sizing of Apparel for Young Men Students)," NBS Voluntary Product Standard (PS 45-71), National Bureau of Standards, January 1972.

*This Voluntary Product Standard covers size categories, size designations, and body measurements for the sizing of apparel for boys designated young men or students. The young men (students) category is intended to include those boys and young men who have achieved most of their adult height, but not adult girth. The Standard includes the following: applications of the body sizing system, methods of measuring the body, an explanation of the development of the Standard, and sizing grades. Also included is a method of identifying products that are sized using the measurements and designations in this Standard.

\section{"Body Measurements for the Sizing of Girls' Apparel," NBS Voluntary Product Standard} (PS 54-72), National Bureau of Standards, July 1973.

*This Voluntary Product Standard establishes a nationally recognized sizing system for girls, based on body measurements. The standard covers three classifications: slims, regulars, and chubbies. In each classification, sizes 7, 8, 10,12, 14 and 16 are defined by 33 body measurements.

\section{"A Single Standard Sizing System for Clothes," Textile Industries Dyegest- Southern Africa, p. 10, October 1991.}

Due to the diversity in human body shapes and proportions, it is not feasible to construct a single set of garment sizes that could be applied universally. A sizing system that is based on open-ended dimensional scales of preferred numbers and common inter-size intervals has been approved by the ISO. It is planned to implement the system in 1992. 


\section{REFERENCE}

[1] Lee, Y. T., "Apparel Product Data Exchange Standard," Proceedings of the Third Annual Apparel Research Conference: Implementing Advanced Technology, Atlanta, GA, February 1992

[2] Moncarz, H. T., and Lee, Y. T., "Report on Scoping the Apparel Manufacturing Enterprise," Volume 5, Number 3/4, International Journal of Clothing Science and Technology, MCB University Press Limited, Bradford, UK, 1993

[3] Lee, Y. T., and Moncarz, H.T., "A Prototype Application Protocol for Ready-to-Wear Pattern Making," NISTIR 5115, National Institute of Standards and Technology, Gaithersburg, MD, January 1993

\section{ACKNOWLEDGEMENT}

The author of this report would like to thank Michael E. Read for his assistance in conducting the literature survey. Without his help, it would not have been possible to complete this report. 

